\title{
Intra-maze cues and alternation after forced trials'
}

Rats were given four forced trials and one free trial each day for 15 days. The use of an opaque or clear door to block the nonforced arm did not influence altemation. When one arm was black and the other was white, more alternation occurred when the same maze arms were used for forced and free trials than when new arms were used for the free trials.

Alternation by rats in mazes is currently explained in terms of stimulus satiation or exploring novel stimuli (Bernhardson, 1965). Thus the stimulus satiation theory states that alternation occurs after forced trials because stimulus satiation has reduced the tendency to respond to the forced arm, while the other theory states that alternation is due to exploring the novel stimuli in the nonforced arm. The present study was designed to test predictions that these two theories make about the effect of the type of door used in forcing and the effect of nonvisual cues. Method

The Ss were 64 albino rats ( 32 males and 32 females) from the colony in the Psychology Department at Michigan State University. They were at least 80 days old at the beginning of the experiment. They were on a diet of $10 \mathrm{gm}$ of Wayne Lab Blox per $24 \mathrm{hr}$., but water was ad lib.

The apparatus consisted of an enclosed T-maze. The first 10 in. of the 25 in. stem was the start box. The removable arms were each 20 in. long. The food cup was behind a baffle so it could not be seen from the choice point. All alleys had an inside width of 4 in. and an inside height of 5-1/2 in. The start box was covered by a hinged wooden lid and the alleys were covered with hardware cloth. Half of the Ss were run in a maze with one black arm and one white arm with a stem of natural wood covered with clear varnish (B-W Condition), and half of the Ss were run in a maze with both arms of natural wood covered with clear varnish and a stem with one side black and one side white ( $\mathrm{N}-\mathrm{N}$ Condition). To prevent retracing, a masonite guillotine door was at the end of the start box and either masonite or clear plastic doors were at the entrance to each arm.

A shield consisting of three sides and a roof was placed over the maze to make the extra-maze cues homogeneous. The open side faced a wall covered by a large window blind. Light was provided by the regular lights in the room and a $25-\mathrm{W}$ bulb on the shield $32-1 / 2$ in. above the choice point.

For the first 13 days the $\mathrm{Ss}$ were handled for $3 \mathrm{~min}$. before their dally feeding. In addition, each $\mathrm{S}$ was allowed to eat five $45-\mathrm{mg}$ Noyes reward pellets from a food cup on days 9,10 , and 11 . The Ss were given one pretraining trial in a straight alley on days 12 and 13, two massed pretraining trials on days 14 and 15 , and five massed pretraining trials on days 16 and 17. The reward on each pretraining trial was two $45-\mathrm{mg}$ Noyes reward pellets.

Beginning on day 18 , the Ss were given four forced trials and one free trial each day for 15 days. On the forced trials the guillotine door at the end of the start box was opened $10 \mathrm{sec}$. after the $\mathrm{S}$ was placed in the start box, and the $S$ was returned to the start box after it ate the two 45-mg reward pellets. After the forced trials, each $S$ was placed for $1 \mathrm{~min}$. in a $11-7 / 8$ in. $x \quad 11-3 / 4$ in. $x \quad 7-5 / 8$ in. holding box situated on the floor below the stem of the maze. Then each $S$ was given a free trial. The usual reward was available on the free trials in the arm which had previously been the forced arm.

Two experimental conditions were manipulated. The type of door used to block the nonforced arm was varied by using transparent plastic doors (TD) for half the Ss and opaque masonite doors (OD) for the other Ss. The previous experience with the maze arms used on the free trials was manipulated by giving half of the Ss the same arms which had been used on the forced trials (PE) and giving half of the Ss new maze arms which were identical to the ones which had been used on the forced trials (NPE).

\section{Results}

The results were analyzed separately as a 2 by 2 by 3 factorial design in which two of the factors were treatments and the third factor was blocks of trials (Edwards, 1962) for the B-W Condition and the $\mathrm{N}-\mathrm{N}$ Condition. The factors were type of door (TD vs. OD), previous experience in the arms used on the free trials (PE vs. NPE), and blocks of five free trials. The number of alternations by the eight Ss given each type of treatment is summarized in Table 1.

For the B-W Condition there was significantly more alternation when the arms used on the free trials had

Table 1. Number of altemations on blocks of five free trials under different experimental treatments

\begin{tabular}{lcccccc} 
Experimental & \multicolumn{3}{c}{ B-W Condition } & \multicolumn{3}{c}{ N-N Condition } \\
treatment & $1-5$ & $6-10$ & $11-15$ & $1-5$ & $6-10$ & $11-15$ \\
\hline TD - NPE & 22 & 22 & 12 & 20 & 20 & 22 \\
TD - PE & 24 & 27 & 24 & 24 & 23 & 26 \\
OD - NPE & 28 & 18 & 10 & 32 & 33 & 25 \\
OD - PE & 35 & 35 & 23 & 28 & 27 & 26 \\
\hline
\end{tabular}


been used on the forced trials (PE) than when the arms used on the free trials had not been used on the forced trials (NPE) $(F=4.91, \mathrm{df}=1 / 28, \mathrm{p}<.05)$. There was also a significant decline in alternation over blocks of trials $(F=7.39, d f=2 / 56, p<.01)$. None of the comparisons were significant for the $\mathrm{N}-\mathrm{N}$ Condition. Discussion

Both the stimulus satiation and exploration theories would predict more alternation for an opaque guillotine door than for a transparent guillotine door. The stimulus satiation theory would predict this because the Ss cannot build up satiation for the stimuli of the nonforced arm on forced trials when an opaque door is used. However, the use of a transparent door does permit some buildup of satiation for the nonforced arm on forced trials. The exploration theory would make this prediction because the stimuli of the nonforced arm would be more novel if they had been hidden by an opaque door than if they had been viewed through a transparent door. In addition, removing an opaque door for the free trial would make a larger change at the choice point and thus be more likely to attract attention to the nonforced arm. The results of this study, however, did not support these predictions and are in harmony with previous work with alternation after one free trial, which indicated that the odor trail was the only intra-maze cue that was effective (Douglas, 1964).

Both theories would also predict more alternation when the same arms were used for forced trials and free trials than when new but identical arms were substituted for the free trials. The stimulus satiation theory would make this prediction because there would be more satiation for the nonvisual stimuli of the forced arm when the $S$ had been exposed to these stimuli on the forced trials than when the $S$ had not been exposed to these stimuli on the forced trials. The exploration theory would make this prediction because the nonvisual stimuli of both arms on the free trials would be equally novel when these arms had not been experienced on the forced trials. The results of this study supported this prediction only for the B-W Condition. Previous research has shown alternation on the basis of nonvisual cues because blind rats have alternated in a $\mathrm{T}$-maze (Dember \& Roberts, 1958) and in a cross-maze (Dember, 1958). It seems reasonable that the nonvisual cue which was being used was the S's odor trail (Douglas, 1964).

\section{References}

Bermhardson, C. S. Stimulus change versus stimulus satiation and forcing versus nonforcing in relation to alternation. Unpublished doctoral dissertation, Michigan State University, 1965.

Dember, $\boldsymbol{W}$. N. Stimulus alternation in peripherally blinded rats. Canad. J. Psychol., 1958, 12, 219-221.

Dember, W. N., \& Roberts, W. W. Alternation behavior in peripheral ly blinded rats. Percept. mot. Skills, 1958, 8, 91-94.

Douglas, R.J. An analysis of spontaneous alternation cues. Unpublished doctoral dissertation, University of Michigan, 1965.

Edwards, A. L. Experimental design in psychological research. New York: Holt, Rinehart and Winston, 1962.

\section{Note}

1. This study represents a part of the author's doctoral dissertation done at Michigan State University, 1965. The author would like to thank his supervisor, Dr. M. Ray Denny, for his guidance. 